\title{
MOBILIDADE URBANA NO MUNICÍPIO DE PRESIDENTE PRUDENTE
}

\author{
Mariana Pompei Pinheiro, Korina Aparecida Teixeira Ferreira da Costa
}

Universidade do Oeste Paulista - UNOESTE, Curso de Arquitetura e Urbanismo, Presidente Prudente, SP. E-mail: mariana_pompei@hotmail.com

\section{RESUMO}

A mobilidade urbana é um dos aspectos principais no funcionamento do espaço urbano e representa um demarcador da condição e do desempenho das cidades. Por isso, as condições de deslocamentos através dos diferentes modais de transporte e as situações de integração entre eles podem e devem ser adotados para resultar numa condição eficiente de circulação dentro da malha viária.Diante disso, o presente trabalho discute a formulação do plano de mobilidade (2014) para o município de Presidente Prudente, que se deu no sentido de nortear a implementação mais frequente de modais alternativos de transporte e remodelar os demais modais a fim de otimizar a circulação urbana na cidade.

Palavras - chave:Mobilidade urbana; modais de transporte

\section{URBAN MOBILITY IN THE PRESIDENTE PRUDENTE CITY}

\begin{abstract}
Urban mobility is a main aspect in the operation of urban space and represents a path of the condition and performance of cities. Therefore, the conditions of displacement through the different transport modes and situations of integration between them can and should be adopted to result in efficient condition of circulation inside of city. Therefore, the current survey discusses the mobility plan formulation (2014) for the city of PresidentePrudente, elaborated with the goal to guide the most frequent implementation of alternative modes of transportation and to reshape other modes in order to optimize urban traffic in the city.
\end{abstract}

Keywords: Urban mobility; transportation modes 


\section{INTRODUÇÃO}

O presente estudo é desenvolvido com base nas condições de deslocamento dentro das cidades, da qual a necessidade de circulação é vista como função primordial aofuncionamento das atividades cotidianas. A prática do deslocamento acontece, segundo MENDONÇA (2008), em função das vontades e necessidades de sobrevivência que as pessoas possuem através de diversas atividades exercidas. Estas, por sua vez, dependem além das condições socioeconômicas da população, das condições espaciais do território a ser percorrido.

Ao longo da evolução da história, a fim de suprir as principais necessidades das sociedades, o desenvolvimento dos transportes tornou possível a interação das relações vivenciadas pelo homem em seu território correspondente, bem como passou a contribuir para a promoção da acessibilidade e mobilidade no meio urbano, garantindo às pessoas e bens a função de circulação. Além disso, o sistema de trânsito e transporte de uma cidade é um dos indicadores de seu desempenho (MARCHIORO, 2014).

É importante ressaltar neste estudo, que no Brasil os deslocamentos são feitos principalmente - com hegemonia - através do modal rodoviário, em detrimento de outras modalidades de transporte. Isso se desenvolveu ao longo do tempo, porque historicamente o Brasil priorizou investimentos na malha rodoviária na totalidade de seu território, principalmente pela injeção de capital da indústria automobilística na Déc. de 50 , beneficiando a economia brasileira (SCHROEDER e CASTRO, 1996).

Tendo em vista a importância da função de circular no contexto urbano, a temática da mobilidade urbana vem sendo cada mais discutida, umas vez que é ponto chave no desenvolvimento das cidades e nas atividades essenciais das várias parcelas da sociedade (MARCHIORO, 2014). Acrescentando, muito intrínseco ao conceito de mobilidade, está o ideal de integração entre os modais de transporte existentes nas cidades, como forma de não super utilizar somente um tipo de modal e garantindo à população o acesso democrático à cidade de formas alternativas ao convencional, sugerindo até mesmo uma melhoria na qualidade de vida, por exemplo, quando citamos a possibilidade de movimentação a pé ou por meio cicloviário.

\section{METODOLOGIA}

A metodologia baseia-se numa investigação bibliográfica e se fundamenta numa abordagem qualitativa de pesquisa, utilizando-se como instrumento um levantamento bibliográfico e documental, que segundo Teixeira (2000, p. 137), busca a correlação entre a teoria e os dados, entre o contexto e a ação, a partir da compreensão dos fenômenos por meio de sua 
descrição e interpretação. Para o trabalho com o estudo do tipo de levantamento bibliográfico ocorreu inicialmente um levantamento das principais produções no contexto nacional de estudos, considerando a peculiaridade do objeto de estudo.

Desse modo, percebe-se que a pesquisa qualitativa vale-se do método indutivo, segundo o qual parte da observação, da análise dos fatos particulares, dos registros para compor um quadro compreensivo para então constituir a generalização universal, ou seja, a teoria. O processo de indução vale-se do princípio do empirismo, no qual o conhecer é dar significado à realidade (KÖCHE, 1997, p. 62).

\section{MODAIS DE TRANSPORTE X MOBILIDADE URBANA}

O termo transporte urbano é usado para determinar a ação dos deslocamentos das pessoas e cargas nas cidades, o que segundo FERRAZ E TORRES (2001) ocorre por diversos motivos, como trabalho, estudo, compras, lazer, ou mesmo para a obtenção de serviços específicos.

Para a efetivação dos deslocamentos, a população se vale de diferentes modos de transporte como a pé, de bicicleta, com o uso de motocicletas, carros, ônibus, trens, bondes, embarcações, etc., que podem variar segundo a cultura e as condições socioeconômicas dos usuários (FERRAZ E TORRES, 2001).

A seguir, analisaremos alguns dos possíveis modos de efetuar os deslocamentos no contexto urbano, abordando a importância de cada um e como são empregadas em território nacional.

\section{Deslocamentos a pé}

Mesmo com a possibilidade de uso dos demais tipos de transporte pela cidade, as pessoas necessitam deslocar-se como pedestres em suas incumbências. Portanto, para permitir a circulação das pessoas por seu esforço próprio, os passeios públicos - ou calçadas - constituem-se como equipamento essencial no meio urbano; e devem ser projetados para propiciar a acessibilidade aos locais por qualquer indivíduocom o máximo de conforto e segurança.

Em suma, a qualidade da utilização das calçadas para os deslocamentos a pé depende muito das condições físicas do trajeto, da oferta de serviços e locais movimentados que garantam dinamismo e segurança no percurso, bem como do auxílio da arborização durante o dia e da instalação de iluminação pública eficiente no período noturno (MARCHIORO, 2014). 


\section{Bicicleta}

O modal cicloviário é bastante utilizado para viagens urbanas, principalmente pelo seu baixo custo de aquisição, manutenção e operação por seus usuários. Representa também um sistema de transporte ecologicamente correto, haja vista que utiliza o próprio esforço humano, não consumindo combustível e consequentemente não liberando poluentes na atmosfera (FERRAZ E TORRES, 2001).

Apesar de o uso da bicicleta ser atualmente indicado como uma alternativa barata e sustentável para os deslocamentos individuais, MARCHIORO (2014) levanta o fato da fragilidade do ciclista em meio ao sistema viário urbano e da ineficiência desta rede no Brasil, já que as ciclofaixas exclusivas são geralmente interruptas, sem continuidade no trajeto.

As viagens dos ciclistas, influenciadas pela cultura da população, bem como pelas condições topográficas da cidade, devem ser encaradas pelos órgãos municipais como uma possível solução para desafogar o trânsito pesado, objetivando menores índices de impactos ambientais, acesso democrático ao território e o aumento da qualidade de vida dos usuários.

\section{Carros - Veículos particulares}

No Brasil, o setor de transportes de cargas e passageiros é majoritariamente tomado pelo modal rodoviário, principalmente através do modo individual em detrimento do transporte coletivo, utilizando-se de veículos motorizados e da infraestrutura viária de nossas cidades.

O uso do carro como transporte predominante decorre de sua produção em grande escala dentro do país, o que consequentemente passa a baratear seu custo, tornando-se um objeto de compra mais acessível (FERRAZ E TORREZ, 2001).

Entretanto, o modelo vigente de transporte é responsável por acarretar muitos problemas, tais como acidentes, ocupação exacerbada das vias, acarretando congestionamentos; poluição do ar e sonora; subtração de áreas públicas para priorizar a infraestrutura do modelo rodoviário, etc. Para VACONCELLOS (2000)há uma priorização indevida do transporte individual sobre o transporte coletivo, voltado a quem pode financiá-lo.

\section{Transporte Público}

O transporte coletivo público, é visto hoje como uma das principais alternativas para o funcionamento do sistema de mobilidade urbana, já que possui uma grande capacidade de transporte de passageiros, se comparado ao transporte motorizado individual (carros, caminhonetes, motos, etc.). Contudo, é sabido que ao longo do tempo e até os dias de hoje, os 
investimentos em transporte público são suprimidos para ceder lugar ao transporte individual, já que por trás deste desdobramento, há maior lucratividade das indústrias automobilísticas e maior movimentação de capital.

Todavia, não é possível incentivar o uso do transporte coletivo, se este sistema não atende as necessidades de seus usuários de forma eficiente, deixando de garantir segurança, conforto, viagens rápidas e sem cobrir as diversas partes da cidade(DUARTE; SÁNCHEZ; LIBARDI, 2012). Portanto, os investimentos neste setor seriam de grande relevância para o aumento da qualidade de vida das populações urbanas, pois ajudariam a mitigar os problemas decorrentes da valorização do automóvel particular.

No Brasil, a maior parte dos deslocamentos do sistema público de transporte é feito através dos ônibus, segundo DUARTE; SÁNCHEZ; LIBARDI (2012).

Os modais citados anteriormente são alguns dos mais utilizados em território nacional e que contribuem para o sentido de mobilidade urbana, sendo este conceito um requisito fundamental para o desenvolvimento das funções que a cidade exige, garantindo às pessoas o acesso democrático aos espaços públicos e auxiliando em suas articulações essenciais como nas áreas produtivas, comerciais, de moradia, trabalho, consumo, educação e lazer (MARCHIORO, 2014).

A fim de basear mais profundamente a discussão sobre mobilidade urbana, cita-se ainda a Lei Federal no 12.587, de 3 de janeiro de 2012, que institui diretrizes da Política Nacional de Mobilidade Urbana, embasada nos princípios de acessibilidade de todos os indivíduos, garantindo a equidade do uso dos espaços públicos da cidade; na formação e desenvolvimento sustentável das cidades, nas esferas socioeconômicas e ambientais, a fim de promover melhores condições de vida e saúde da população; na eficiência e eficácia nos serviços oferecidos pelo sistema de transporte urbano; no incentivo aos meios não motorizados de transporte e ao desenvolvimento dos meios científico-tecnológicos e uso de fontes de energia renováveis, a fim de amenizar a emissão de poluentes dos combustíveis fósseis utilizados em larga escala.

\section{DISCUSSÃO}

Para auxiliar na promoção da mobilidade urbana no município de Presidente Prudente oeste do estado de São Paulo - principalmente em decorrência do uso majoritário do veículo particular e pela necessidade emergente de novas alternativas de circulação na cidade, foi elaborado em 2014 um plano de mobilidade urbana para o município, do qual prioriza alguns 
aspectos comoo Projeto de Reestruturação do Transporte Coletivo, Projeto de Tratamento Dos Pontos Críticos, Projeto Calçada Legal e o Projeto da Rede Cicloviária Integrada.

Para cada segmento foram sugeridas soluções e diretrizes a fim de tornar o sistema de circulação da cidade mais eficiente; portanto o Projeto de Reestruturação do Transporte Coletivo sugere uma nova rede de transporte coletivo interligada por estações de integração espalhadas pelas diferentes regiões do município, da qual se torna mais acessível e bem equipada, com a criação de equipamentos urbanos voltado à função, bem como de linhas de transporte capazes de abranger maior parcela da cidade. Para o Projeto de Tratamentos Críticos, o desenvolvimento do estudo se deu no sentido de reconhecer as áreas de maiores índices de fluxo e consequente congestionamento, principalmente próximo a instituições de ensino, comércio ou saúde, na tentativa de mitigar seus efeitos com a implementação de medidas como faixas exclusivas de circulação de ônibus ou ciclistas, rotas de exclusão de circulação de veículos pesados ou mudanças na estrutura física das vias, como implantação de rótulas e canteiros. O conceito do Projeto Calçada Legal é tornar os passeios públicos locais de livre acesso e circulação sem impedimentos a qualquer tipo de individuo, seja qual for sua limitação, dando prioridade ao pedestre e o incluindo nos processos de integração de modais, como por exemplo a pé-bicicleta-transporte coletivo. Por fim, o Projeto Rede Cicloviária Integrada visa dotar a cidade de infraestrutura específica para o uso, para que os trajetos de bicicleta se tornem mais uma opção de circulação no município de maneira continuada, na tentativa de garantir segurança viária, rotas diretas e rápidas, coerência na estrutura, conforto e atratividade.

Os pontos de estudo desenvolvidos para o plano visam, de forma integrada,fomentar o direcionamento da cidade de maneira ordenada, priorizando os pedestres, ciclistas e o transporte coletivo (MARCHIORO, 2014).

\section{CONSIDERAÇÕES FINAIS}

Tendo em vista a importância da mobilidade urbana no contexto das cidades, e em especial, da cidade de Presidente Prudente, a elaboração de um Plano de Mobilidade Urbana único e exclusivo para a nossa realidade é de grande significância para o município, uma vez que sugere passos a serem seguidos quanto às ações de planejamento e gestão que podem ser adotadas pelo Poder Público, onde o conceito de gestão está ligado ao ato de gerir no presente e o ato de planejamento visando solucionar problemas futuros, que podem ser previstos, segundo SOUZA (2001). Ou seja, é através dos estudos de caso de cada área e setor da cidade, sendo possível conhecer cada condicionante e problemática existente, que o governo municipal pode 
agir para aumentar a eficiência das circulações no contexto urbano, objetivando uma melhor relação entre os agentes envolvidos e aumentando a qualidade de vida da população.

Atualmente no município já se começa a observar a aplicação de alguns itens propostos pelo Plano, como a implementação de ciclovias e a demarcação dos locais indicados para as estações de integração de transporte coletivo, porém de forma morosa. Diante do proposto e da bagagem histórica que o Brasil detémacerca da ausência de planejamento, ou mesmo da vigência de planejamento e gestão em prol do interesse privado e do capital, é necessário que a população seja o principal agente de fiscalização dos serviços e melhorias propostas, cabendo a indagação de quando e como serão efetivadas estas soluções capazes de aumentar a eficiência das relações de circulação na cidade.

\section{REFERÊNCIAS}

DUARTE, F.; SÁNCHEZ, K.; LIBARDI, R. Introdução à mobilidade urbana. Jurua Editora, 2012.

FERRAZ, A. C. P.; TORRES, I. G. E. Transporte público urbano. RiMa Editora, 2001.

MARCHIORO, E. Plano de mobilidade urbana de Presidente Prudente. Relatório técnico 01. 2014.

MENDONÇA, A. C. Desenvolvimento de um modelo de previsão da demanda de passageiros do transporte rodoviário interestadual utilizando regressão com efeitos espaciais locais. 2008. 123 f. Dissertação (Mestrado em Transportes)-Universidade de Brasília, Brasília, 2008.

SCHROEDER, E. M.; CASTRO, J. C. Transporte Rodoviário de Carga: situação atual e perspectivas. Revista do BNDES, n. 6, 1996.

SOUZA, M. J. L. Mudar a cidade: uma introdução crítica ao planejamento e à gestão urbanos. Bertrand Brasil, 2001.

VASCONCELLOS, E. A. Transporte urbano nos países em desenvolvimento: reflexões e propostas. Annablume, 2000.

KÖCHE, J. C. Fundamentos de metodologia científica: teoria da ciência e iniciação à pesquisa. 22 . ed. São Paulo: Vozes, 2004.

TEIXEIRA, E. As três metodologias. 2a .ed. São Paulo: Vozes, 2000. 